\title{
Locus of Control and Its Associations with Depressive Symptoms amongst People with Dementia
}

\author{
Ingeborg Halse ${ }^{a, b, c}$ Guro Hanevold Bjørkløf ${ }^{a} \quad$ Knut Engedal $^{a, b}$ Geir Selbæk ${ }^{a, b, c}$ \\ Maria Lage Barca ${ }^{a}$ b
}

aNorwegian National Advisory Unit on Ageing and Health, Vestfold Hospital Trust, Tønsberg, Norway; bepartment of Geriatric Medicine, Oslo University Hospital-Ullevaal, Oslo, Norway; ${ }^{C}$ Faculty of Medicine, University of Oslo, Oslo, Norway

\author{
Keywords \\ Dementia · Locus of control · Depression · Coping · \\ Psychosocial interventions
}

\begin{abstract}
Introduction: Depression is common amongst people with dementia. This study examines whether locus of control (LoC), a perceived control construct influential in the coping process, is related to depressive symptoms in this population. Methods: In this prospective observational study, 257 community-dwelling older adults with a confirmed dementia diagnosis were included. At baseline, measures of depressive symptoms, LoC, cognition, independent functional ability, general health, dementia severity, and dementia disease insight were collected. At follow-up, measures of depressive symptoms and cognition were collected. Multiple linear regression using degree of depressive symptoms as measured with Montgomery-Asberg Depression Rating Scale as a dependent variable was applied to assess whether LoC was associated with depressive symptoms at baseline and followup while controlling for covariates. Results: LoC $(p<0.001)$, general health $(p=0.003)$, and insight $(p=0.010)$ were associated with severity of depressive symptoms at baseline, ac-
\end{abstract}

karger@karger.com www.karger.com/dem

Karger $\stackrel{\text { ' }}{5}$
C 2021 The Author(s)

Published by S. Karger AG, Basel

This is an Open Access article licensed under the Creative Commons Attribution-NonCommercial-4.0 International License (CC BY-NC) (http://www.karger.com/Services/OpenAccessLicense), applicable to the online version of the article only. Usage and distribution for commercial purposes requires written permission. counting for $28 \%$ of the variance. LoC $(p=0.025)$ and depressive symptoms $(p<0.001)$ at baseline were associated with severity of depressive symptoms at follow-up, accounting for $56.3 \%$ of the variance. Conclusion: LoC was significantly associated with severity of depressive symptoms in people with dementia at baseline and at follow-up. Attention to LoC may be valuable for our understanding of depression in people with dementia, and interventions targeting depression could benefit from including a focus on internalizing perceived control. However, these findings are novel, and more research is needed.

(c) 2021 The Author(s)

Published by S. Karger AG, Basel

\section{Introduction}

The number of people with dementia is increasing globally, and a recent population study in Norway has found a $14.6 \%$ prevalence rate amongst those aged 70 years or older [1]. As no cure is imminent, supporting people to live well with dementia should be a priority for health-care and social service providers. Depression is common amongst people with dementia [2-4] and can lead to or exacerbate cognitive decline [5-7], reduced 
quality of life [8-10], and reduced functioning in daily living [3]. As in the general population, depression amongst people with dementia is a disorder that can be related to biopsychosocial risk factors, such as the degree of cognitive decline and insight into this decline, prior depression disorder, general health, and residing in an assisted-living facility, all factors that are difficult to modify $[5,11-15]$. However, little is known about psychological risk factors and, especially, how depression amongst people with dementia is associated with the perception of control.

Perceived control is recognized as a fundamental human goal because people want to interact effectively in any situation [16]. For decades, studies have shown perceived control to be an influential aspect of the coping process affecting how individuals appraise stressful situations and the available resources for managing them [16]. In relation to health issues, greater perceived control is associated with better treatment adherence, healthy behaviours, and better adaptation to chronic conditions [17-19].

Self-efficacy, mastery, learnt helplessness, and locus of control (LoC) are examples of the most commonly studied constructs of perceived control [20-23]. LoC is defined as the degree to which a person expects occurrences in life to be due to his or her own actions, considered internal control, or due to actions of others or chance, both considered external control [20]. In general, people tend to cope more efficiently with stress they perceive as controllable, which also prevents stress from becoming overwhelming and potentially triggering symptoms of depression and anxiety [24].

LoC has repeatedly been linked to depression among older persons and persons coping with chronic illness, and findings from both cross-sectional and prospective studies show external LoC to be associated with increased severity of depressive symptoms [25-28]. Even though dementia profoundly affects cognition, independent functional ability, and autonomy, perceived control beliefs remain largely unexamined in the scientific literature focussing on people with dementia. A systematic review of research conducted with people with dementia using a control belief questionnaire revealed 18 eligible studies [29]. None of the studies reported methodological difficulties with using such questionnaires, and internal reliability was reported as ranging from acceptable to good [29].

Depressive symptoms were measured in 10 of the studies in the review, but only 2 looked at the association with control beliefs. Fankhauser et al. [30] measured self- efficacy as part of a composite measure that also included decision regulation, activation regulation, and motivation regulation. They found that the composite measure predicted depression, also when controlling for variables such as age, gender, cognition, and dementia severity. Halse et al. [31] found more external LoC as being associated with more depressive symptoms but no association between cognition and LoC. In addition, a pilot intervention study examining feasibility of a self-management course resulted in mean increases in self-efficacy and decreases in depression; however, neither a direct association was examined nor a statistical significance was found due to a small sample size [32]. In summary, regardless of a growing interest in examining perceived control amongst people with dementia, little is known about its relationship with depression in this group.

\section{Aims and Hypotheses}

The present study aimed to examine the degree to which LoC is associated with depressive symptoms when controlling for sociodemographic and clinical variables related to depression in a sample of persons diagnosed with dementia. We hypothesized that more external LoC is associated with increased severity of depressive symptoms at baseline and, furthermore, that more external LoC is associated with increased severity of depressive symptoms at a 12-month follow-up.

\section{Methods}

Design

This is a prospective observational study with a 12 -month follow-up. It is part of a larger project called "Effects and Cost of a Day Care Centre Program Designed for People with Dementia" (ECOD), which studies the effectiveness of the Norwegian day service programme for people with dementia. The project recruited participants from 2013 to 2015. For more details about the project, see Rokstad et al. [33].

\section{Participants}

All 257 participants in the ECOD project were included in the current study. The inclusion criteria for the project were being 65 years of age or older, having a dementia diagnosis and a MiniMental Status Examination-Norwegian Revised (MMSE-NR) minimum score of 15 , residing at home, and having the ability to give informed consent for participation. Participants were recruited from day care centres designed for people with dementia and by in-home nursing service providers. To ensure all participants had a dementia diagnosis, 2 specialists in geriatric psychiatry (authors K.E. and M.B.) used baseline information to confirm dementia diagnoses as defined by the research criteria of ICD-10 [33, 34]. 
Table 1. Description of participants' sociodemographic and clinical characteristics at baseline

\begin{tabular}{|c|c|c|c|}
\hline \multirow[t]{2}{*}{ Characteristic (assessed subjects, $n$ ) } & \multicolumn{2}{|l|}{ Baseline } & \multirow[t]{2}{*}{$p$ value } \\
\hline & female $(n=168)$ & male $(n=89)$ & \\
\hline Age, mean (SD), $(n=257)$ & $81.54(6.6)$ & $81.48(6.0)$ & $0.950^{1}$ \\
\hline Married (or de facto married), $N(\%),(n=255)$ & $37(22.0)$ & $62(71.3)$ & $<0.001^{2}$ \\
\hline Education $>10$ years, $N(\%),(n=249)$ & $67(41.1)$ & $45(52.3)$ & $0.119^{2}$ \\
\hline Attendance at day care, $N(\%),(n=257)$ & $111(66.1)$ & $71(78.9)$ & $0.031^{2}$ \\
\hline Good or very good physical health, $N(\%),(n=240)$ & $123(78.9)$ & $63(75.0)$ & $0.697^{2}$ \\
\hline$N$ of prescription medications, mean $(\mathrm{SD})^{4},(n=257)$ & $4.73(2.74)$ & $4.88(2.50)$ & $0.670^{1}$ \\
\hline Has had prior depression, $N(\%),(n=257)$ & $28(16.7)$ & $5(5.6)$ & $0.020^{2}$ \\
\hline Full/partial insight of dementia disease, $N(\%),(n=252)$ & $150(90.9)$ & $80(92.0)$ & $0.938^{2}$ \\
\hline LoC, mean $(\mathrm{SD}),(n=182)$ & $30.8(11.15)$ & $31.15(12.12)$ & $0.837^{1}$ \\
\hline Depressive symptoms, mean (SD), $(n=246)$ & $5.5(4.98)$ & $4.5(5.17)$ & $0.024^{3}$ \\
\hline Cognitive function, mean (SD), $(n=256)$ & $20.55(3.50)$ & $20.19(3.44)$ & $0.397^{3}$ \\
\hline Dementia severity, mean (SD), $(n=253)$ & $5.93(2.35)$ & $7.30(2.67)$ & $<0.001^{1}$ \\
\hline Functional ability, mean (SD), $(n=251)$ & $20.68(5.31)$ & $24.38(4.41)$ & $<0.001^{3}$ \\
\hline
\end{tabular}

LoC, locus of control. ${ }^{1}$ Independent samples $t$ test. ${ }^{2} \chi^{2}$ test for independence. ${ }^{3}$ Mann-Whitney test. ${ }^{4}$ Potential ceiling effect, as maximum number reported was restricted to 9 different prescription medications.

Most of the participants had Alzheimer's disease (78.6\%), followed by vascular dementia (8.6\%), mixed Alzheimer's/vascular (5.4\%), Lewy Body or Parkinson's disease with dementia (5.1\%), frontotemporal dementia (0.8\%), and other dementias (1.6\%). The mean age was 81.5 years (SD 6.4), and $168(65.4 \%)$ participants were women. After 12 months, 138 participants remained in the study. Reasons for attrition were admittance to a long-term living facility, withdrawal from the study, or death.

\section{Assessments}

The participants were interviewed either at home or at a day care centre. At baseline, sociodemographic and clinical characteristics were recorded. The participants were assessed with the instruments listed below both at baseline and at 12 months. For the present study, only measures of depressive symptoms and cognitive function were used of the follow-up data.

The Locus of Control of Behavior Scale (LOCB) was used to measure LoC orientation [35]. It consists of 17 items, with a total score ranging from zero to 85 . Higher scores indicate a higher degree of external orientation. The scale has been translated to Norwegian and back-translated [36] and has been applied in several Norwegian studies with older participants [37-39]. In a study examining its applicability to people with dementia, Cronbach's alpha (internal reliability) was at a satisfactory level of 0.69 and remained at 0.73 even among those with MMSE-NR score between 15 and 19 [31]. The Cronbach's alpha in the present study was 0.70 .

The Montgomery-Asberg Depression Rating Scale (MADRS) was used to measure depressive symptoms. It consists of 10 items, with possible scores ranging from zero to 60 and higher scores indicating more severe symptomatology [40]. The Norwegian version has been validated for use with people diagnosed with dementia, and the best cutoff indicating depression was $6 / 7$ points [41].

The revised Norwegian version of the MMSE-NR was used to measure global cognition. It consists of 20 items, and the total score ranges from 0 to 30 , with higher scores indicating better cognitive function $[42,43]$.
The Clinical Dementia Rating scale was used to assess dementia severity. It consists of 6 items to assess severity of dementia, and the total score ranges from zero to 18 (sum of boxes method), with zero indicating no impairment and 18 indicating severe impairment $[44,45]$.

The Instrumental Activities of Daily Living Scale was used to measure the ability to perform activities of daily life independently. It consists of 8 items, and the total score ranges from 8 to 31 . Higher scores indicate poorer functional ability [46].

The General Medical Health Rating scale was used to measure physical health. It consists of a single item with 4 categories (poor, fair, good, and excellent [scored 1-4, respectively]). It was developed for use with people who have dementia [47].

The Anosognosia Rating Scale was used to rate the patients' degree of awareness of memory loss. It consists of a single item with 4 categories (full awareness, shallow awareness, no awareness, and denies impairment [scored 1-4, respectively]). The scoring is set based on an interview usually in combination with tests of cognition. Inter-rater reliability has been reported as high (0.91) [48].

\section{Statistics}

The data were analysed using Statistical Package for the Social Sciences, version 27.0. Missing items were imputed if cases had an item response of at least $50 \%$. The missing values were imputed by random numbers drawn from an empirical distribution generated for each item of interest. The imputation was performed by a biostatistician. We assessed variables for normality, and a $p$ value of $<0.05$ was used as the statistical level throughout.

We first examined the sociodemographic and clinical characteristics of the participants using the independent samples $t$ test, $\chi^{2}$ test for independence, or Mann-Whitney test as applicable. The level of education was dichotomized ( $<10$ vs. $>10$ years). We examined the relationship between LoC and the included variables using the independent samples $t$ test, ANOVA, or correlation analysis. Differences between those with complete versus incomplete LOCB and those who remained or were lost to follow-up were as- 
Table 2. Linear regression analyses showing associations between baseline MADRS scores and sociodemographic and clinical variables

\begin{tabular}{|c|c|c|c|c|c|}
\hline \multirow[t]{2}{*}{ Characteristics at baseline } & \multicolumn{2}{|l|}{ Unadjusted reg. analysis } & \multicolumn{3}{|l|}{ Adjusted reg. analysis } \\
\hline & $B(95 \% \mathrm{CI})$ & $p$ value & $B(95 \% \mathrm{CI})$ & $\beta$ & $p$ value \\
\hline Age & $-0.056(-0.156,0.044)$ & 0.269 & $-0.062(-0.170,0.046)$ & -0.078 & 0.260 \\
\hline Gender $($ female $=0 ;$ male $=1)$ & $-0.985(-2.317,0.348)$ & 0.147 & $-0.998(-2.440,0.444)$ & -0.094 & 0.174 \\
\hline Civil status (unmarried $=0$; married $=1$ ) & $0.238(-1.074,1.549)$ & 0.722 & & & \\
\hline Education $(<10$ years $=1 ;>10$ years $=2)$ & $-0.538(-1.837,0.762)$ & 0.416 & & & \\
\hline Attends day care $($ no $=0 ;$ yes $=1)$ & $-1.155(-2.548,0.237)$ & 0.104 & $-0.278(-1.802,1.246)$ & -0.025 & 0.719 \\
\hline LoC & $0.181(0.120,0.241)$ & $<0.001$ & $0.175(0.115,0.234)$ & 0.396 & $<0.001$ \\
\hline Cognitive function & $0.082(-0.100,0.265)$ & 0.377 & & & \\
\hline Dementia severity & $0.104(-0.148,0.357)$ & 0.415 & & & \\
\hline Physical health & $-1.711(-2.592,-0.830)$ & $<0.001$ & $-1.565(-2.599,-0.531)$ & -0.225 & 0.003 \\
\hline Functional ability & $-0.10(-0.131,0.112)$ & 0.879 & & & \\
\hline prescription medications $^{1}, n$ & $0.249(0.011,0.487)$ & 0.040 & $-0.062(-0.344,0.220)$ & -0.032 & 0.666 \\
\hline Prior depression $($ no $=0 ;$ yes $=1)$ & $2.996(1.131,4.862)$ & 0.002 & $1.546(-0.533,3.626)$ & 0.102 & 0.144 \\
\hline Dementia disease insight & $-1.414(-2.470,-0.357)$ & 0.009 & $-1.503(-2.649,-0.357)$ & -0.179 & 0.010 \\
\hline
\end{tabular}

The model explains $28 \%$ of the variance of depressive symptoms at baseline $(F[8,161]=7.825, p<0.001)$. LoC, locus of control; MADRS, Montgomery-Asberg Depression Rating Scale; CI, confidence interval. ${ }^{1}$ Potential ceiling effect, as maximum number reported was restricted to 9 different prescription medications.

sessed using the $\chi^{2}$ test for independence, independent samples $t$ test, or Mann-Whitney test.

Secondly, we performed unadjusted linear regression analyses to examine the associations between the dependent variables (severity of depressive symptoms as measured by MADRS at baseline and at 12 months) and the following independent variables measured at baseline: gender, age, marital status, educational level $(<10$ vs. $>10$ years), day care attendance, general health, number of prescription medications used ( $\max 9)$, history of prior depression, cognition (and change in cognition from baseline to follow-up), dementia severity, degree of insight into dementia disorder, functional ability, and LoC. Gender, age, and variables with a $p$ value of $<0.2$ were examined further in adjusted multiple regression analyses. The models were assessed for multicollinearity, normality, and outliers.

\section{Ethics}

The ECOD project was reviewed and approved by the Regional Committee for Ethics in Medical Research in South-East Norway; REK South-East case number 2013/1020. After receiving written and oral information about the study, participants signed a written consent form. Only those with the capacity to give their consent were included in the study.

\section{Results}

Table 1 shows the baseline sociodemographic and clinical characteristics. Women had higher MADRS scores and were more likely to have had depression previously in life but had less severe dementia and were less dependent on others in daily activities. Men were more likely to be married and to attend day care.

Locus of Control, Depressive Symptoms, and Dementia
A total score on LOCB was obtained for 182 participants. The 75 participants that did not complete the LOCB had more severe dementia, worse cognition, were more dependent in daily activities, and had less education (data not shown). LoC was positively correlated with MADRS measured at baseline (rs [175] $=0.405$ and $p<$ 0.001 ), but not associated with any other variable (data not shown). The 119 participants who were lost to follow-up were at baseline significantly older (mean 82.5 and SD 6.24) than those who remained (mean 80.67 and SD 6.37), but no other differences were found (data not shown).

Table 2 displays the baseline characteristics associated with MADRS scores at baseline. At baseline, more external LoC, poorer general health, using a higher number of prescription medications, having more disease insight, and having previous depression were associated with higher MADRS scores in the unadjusted analysis. In the adjusted analysis, only more external LoC, poorer general health, and having more insight remained significantly associated to the MADRS score at baseline, with LoC being most strongly associated (standardized $\beta=$ 0.396). The model accounted for $28 \%$ of the variance of MADRS scores at baseline $(F[8,161]=7.825$ and $p<$ 0.001 ).

Table 3 displays the baseline characteristics associated with MADRS scores at 12 months. More external LoC, more depressive symptoms, and poorer general health at baseline were associated with higher MADRS scores at 12 
Table 3. Linear regression analyses showing associations between MADRS scores at 12 months and baseline sociodemographic and clinical variables

\begin{tabular}{|c|c|c|c|c|c|}
\hline Characteristics at baseline & \multicolumn{2}{|l|}{ Unadjusted reg. analysis } & \multicolumn{3}{|l|}{ Adjusted reg. analysis } \\
\hline Gender $($ female $=0$; male $=1)$ & $0.468(-1.715,2.651)$ & 0.672 & $1.266(-0.520,3.053)$ & 0.100 & 0.162 \\
\hline Civil status (unmarried $=0 ;$ married $=1$ ) & $0.435(-1.714,2.583)$ & 0.690 & & & \\
\hline Education $(<10$ years $=1 ;>10$ years $=2)$ & $-0.822(-2.948,1.304)$ & 0.446 & & & \\
\hline Depressive symptoms & $0.857(0.709,1.004)$ & $<0.001$ & $0.768(0.580,0.956)$ & 0.645 & $<0.001$ \\
\hline Cognitive function & $-0.088(-0.387,0.210)$ & 0.560 & & & \\
\hline One-year change in cognitive function & $-0.007(-0.338,0.324)$ & 0.966 & & & \\
\hline Dementia severity & $0.069(-0.346,0.484)$ & 0.742 & & & \\
\hline Physical health & $-1.992(-3.418,-0.567)$ & 0.007 & $-0.374(-1.671,0.922$ & -0.045 & 0.568 \\
\hline Functional ability & $0.100(-0.095,0.295)$ & 0.313 & & & \\
\hline
\end{tabular}

The model explains $56.3 \%$ of the variance of depressive symptoms at follow-up $(F[8,92]=14.791, p<0.001)$. LoC, locus of control; MADRS, Montgomery-Asberg Depression Rating Scale; CI, confidence interval. ${ }^{1}$ Potential ceiling effect, as maximum number reported was 9 different prescription medications.

months in the unadjusted analysis. In the adjusted analysis, only more external LoC and MADRS scores at baseline remained significant predictor variables. The model accounted for $56.3 \%$ of the variance of MADRS scores at 12 months $(F[8,92]=14.791$ and $p<0.001)$.

\section{Discussion}

In the present study, we examined whether LoC in people with dementia measured at baseline was associated with severity of depressive symptoms at baseline and at follow-up. Our analyses showed support for both hypotheses. LoC was the independent variable most strongly associated with depressive symptoms at baseline. Also, LoC continued to be associated with depressive symptoms at follow-up, but baseline degree of depressive symptoms was the stronger predictor. In both analyses, there was a positive association between severity of depressive symptoms and more external LoC. To our knowledge, this is the first study to examine the relationship between LoC and depressive symptoms in people with dementia, making comparisons difficult [29]. However, the results are in accordance with findings from systematic reviews and studies on older people with depression $[25,27,28]$.
Regardless of how dementia develops, there is inevitably a fall in function across several domains, and many persons with dementia feel increasingly out of control in their daily life and strive to cope with things they are used to manage [49]. Supporting people to cope with the cognitive, functional, and social consequences of dementia may have positive effects on quality of life and depression $[32,50]$. Successful coping is what prevents stressors from developing into adverse effects such as depression [24]. LoC is one of the several internal resources contributing to the coping process, and our findings indicate that assessing LoC may give additional understanding of depressive symptoms among people with dementia.

Psychosocial interventions for people with dementia are increasing in popularity [51]. Though not necessarily targeting depression, a measure of psychological well-being is usually included as a mean to examine intervention efficacy. A synthesis of 22 systematic reviews examining a variety of psychosocial interventions for people with dementia could not conclude regarding their effects on mood, but several of the included reviews indicated positive effects on depression [52]. Furthermore, group-based cognitive stimulation therapy was found to positively affect quality of life, a construct associated with depression. As depression has been found to be a persistent comorbidity in people with dementia [5], knowledge about cop- 
ing resources such as LoC, and how it relates to both depression and is affected by interventions, is of interest. Indeed, the interest in examining control beliefs among people with dementia appears also to be increasing [29].

To better understand LoC in people with dementia, we examined whether LoC was associated with any of the covariates included in this study. It was interesting to find that the degree of depressive symptoms was the only variable associated with LoC, with a positive correlation of medium strength. In combination with the findings from the regression analyses, this indicates that LoC is a coping resource making independent contributions to depressive symptoms. Few studies have examined LoC or other perceived control beliefs in people with dementia, and the results regarding depression and control beliefs such as self-efficacy, mastery, and LoC remain indicative [30-32, 53-55]. The present findings and those of the review by Halse et al. [29] support a continued focus on control beliefs in this type of research.

Knowledge of which mechanisms lead to effective interventions in people with dementia is relevant to both formal and informal caregivers, and policymakers. Helping people with dementia cope with their disease and live independently longer could prevent premature burden on people with dementia, their families, and society. Increasing the perception of internal control could be 1 such mechanism, potentially leading to empowering effects in the individual. Even the slightest increase in control can make a profound difference in general well-being, as shown in a simple but effective manner in the, now classic, study by Langer and Rodin [56]. The degree to which events are perceived as being a consequence of one's own actions (internal LoC) is part of what motivates a person to feel in control of the situation and thereby act in one's best interest. Indeed, low perception of control has been linked to reduced treatment adherence and a reduced belief in the potential efficacy of an intervention [17]. Conversely, addressing low control expectations of treatment efficacy has been shown to positively affect memory training among older adults with cognitive deficits [57].

As found in other studies, worse physical health and a higher degree of insight into the dementia disease were also associated with more depressive symptoms $[11,12]$. However, we did not find any association between the severity of depressive symptoms and dementia severity, cognition, or independent functional ability, as found by others [15]. A potential reason for this could be that LoC moderates the stress due to dementia. This was found to be the case in a study investigating mastery as a stress moderator buffering the effects of disability on depression in elderly without cognitive deficits [58]. Those who experienced more personal control were less likely to experience depressive symptoms, despite their disabilities.

A limitation of this study is that we were not able to analyse LoC at follow-up due to a low response rate. A potential reason for this may be that the length and complexity of the scale becomes a barrier when cognitive decline has progressed. As Halse et al. [31] found in their study, dementia severity appears to affect response rates, but not necessarily response reliability. It is possible therefore that a less complex control belief instrument could have led to a larger response rate and thereby more information regarding potential changes associated with depression and dementia severity. Finally, it is important to emphasize that we measured degree of depressive symptoms, not depression. Depressive symptoms may overlap with symptoms of dementia; however, the applied instrument for assessing depressive symptoms (MADRS) has been validated for use in dementia with a cutoff of 6/7 indicating depression [41].

\section{Conclusion}

This is the first study to investigate the association between LoC and severity of depressive symptoms amongst people with dementia. We found that LoC was associated with severity of depressive symptoms at baseline and that LoC at baseline predicted depressive symptoms after 12 months. As with adults and older people in general, our findings indicate that attention to LoC may be valuable when understanding depressive symptoms in people with dementia. Interventions that aim to prevent or treat depression in this population may benefit from including a focus on internalizing perception of control. Therefore, further research is needed regarding the relationship between LoC and depression, especially intervention studies that examine the potential amenability of this relationship.

\section{Acknowledgements}

The authors would like to acknowledge the many participating day care centres and in-home care units that participated in the study and those who participated in collecting the data. Finally, we especially thank all the participants who volunteered their time to our study. 


\section{Statement of Ethics}

The project has been accepted by the Regional Committee in Ethics in Medical Research in South-East Norway; REK southeast case numbers 2013/1020 and 2011/531. After written and oral information about the project, the participants were asked to give written informed consent. Only participants with the capacity to give consent were included.

\section{Conflict of Interest Statement}

The authors declare no conflict of interest.

\section{Funding Sources}

The study is part of the ECOD project [32], which is funded by the Research Council of Norway (Grant No. 222083/H10 and 2013058).

\section{Author Contributions}

I.H., G.H.B., K.E., G.S., and M.L.B. jointly designed the study and participated with the statistical considerations and discussion of results. I.H. performed the statistical analysis and wrote the manuscript, with input and revisions from G.H.B., K.E., G.S., and M.L.B. All the authors approved the final version of the manuscript.

\section{Data Availability Statement}

The data that support the findings of this study are available upon request from the corresponding author.

\section{References}

1 Gjøra L, Strand BH, Bergh S, Borza T, Brækhus A, Engedal K, et al. Current and future prevalence estimates of mild cognitive impairment, dementia, and its subtypes in a population-based sample of people 70 years and older in Norway: the HUNT study. J Alzheimers Dis. 2021;79(3):1213-26.

2 Enache D, Winblad B, Aarsland D. Depression in dementia: epidemiology, mechanisms, and treatment. Curr Opin Psychiatry. 2011; 24(6):461-72.

3 Knapskog AB, Barca ML, Engedal K. Prevalence of depression among memory clinic patients as measured by the cornell scale of depression in dementia. Aging Ment Health. 2014 Jul;18(5):579-87.

4 Kitching D. Depression in dementia. Aust Prescr. 2015;38(6):209-2011.

5 Fritze F, Ehrt U, Hortobagyi T, Ballard C, Aarsland D. Depressive symptoms in Alzheimer's disease and lewy body dementia: a one-year follow-up study. Dement Geriatr Cogn Disord. 2011;32(2):143-9.

6 Rapp MA, Schnaider-Beeri M, Wysocki M, Guerrero-Berroa E, Grossman HT, Heinz A, et al. Cognitive decline in patients with dementia as a function of depression. Am J Geriatr Psychiatry. 2011;19(4):357-63.

7 Barca ML, Persson K, Eldholm R, Benth JŠ, Kersten H, Knapskog AB, et al. Trajectories of depressive symptoms and their relationship to the progression of dementia. J Affect Disord. 2017;222:146-52.

8 Naglie G, Hogan DB, Krahn M, Beattie BL, Black SE, MacKnight C, et al. Predictors of patient self-ratings of quality of life in Alzheimer disease: cross-sectional results from the canadian Alzheimer's disease quality of life study. Am J Geriatr Psychiatry. 2011;19(10):881-90.
9 Winter Y, Korchounov A, Zhukova TV, Bertschi NE. Depression in elderly patients with Alzheimer dementia or vascular dementia and its influence on their quality of life. J Neurosci Rural Pract. 2011;2(1):27-32.

10 Barbe C, Jolly D, Morrone I, Wolak-Thierry A, Dramé M, Novella JL, et al. Factors associated with quality of life in patients with $\mathrm{Alz}$ heimer's disease. BMC Geriatr. 2018;18(1): 159-9.

11 Harwood DG, Sultzer DL, Wheatley MV. Impaired insight in Alzheimer disease: association with cognitive deficits, psychiatric symptoms, and behavioral disturbances. Neuropsychiatry Neuropsychol Behav Neurol. 2000 Apr;13(2):83-8.

12 Stroud JM, Steiner V, Iwuagwu C. Predictors of depression among older adults with dementia. Dementia. 2008;7(1):127-38.

13 Rosness TA, Barca ML, Engedal K. Occurrence of depression and its correlates in early onset dementia patients. Int J Geriatr Psychiatry. 2010;25(7):704-11.

14 Barca ML, Engedal K, Laks J, Selbaek G. Factors associated with a depressive disorder in Alzheimer's disease are different from those found for other dementia disorders. Dement Geriatr Cogn Disord Extra. 2012;2(1):19.

15 Steck N, Cooper C, Orgeta V. Investigation of possible risk factors for depression in Alzheimer's disease: a systematic review of the evidence. J Affect Disord. 2018;236: 149-56.

16 Skinner EA, Zimmer-Gembeck MJ. Perceived control and the development of coping. In: Folkman S, editor. The Oxford handbook of stress, health, and coping. Oxford library of psychology. Oxford University Press; 2011. p. 35-59.
17 Choi J, Twamley EW. Cognitive rehabilitation therapies for Alzheimer's disease: a review of methods to improve treatment engagement and self-efficacy. Neuropsychol Rev. 2013;23(1):48-62.

18 Wallston KA. Control beliefs: health perspectives. In: Wrigth JD, editor. International encyclopedia of the social \& behavioral sciences. Elsevier Ltd; 2015. p. 819-21.

19 Robinson SA, Lachman ME. Perceived control and aging: a mini-review and directions for future research. Gerontology. 2017;63(5):435-42.

20 Rotter JB. Generalized expectancies for internal versus external control of reinforcement. Psychol Monogr. 1966;80(1):1-28.

21 Abramson LY, Seligman ME, Teasdale JD. Learned helplessness in humans: critique and reformulation. J Abnorm Psychol. 1978; 87(1):49-74.

22 Bandura A. Self-efficacy: toward a unifying theory of behavioral change. Adv Behav Res Ther. 1978;1(4):139-61.

23 Pearlin LI, Schooler C. The structure of coping. J Health Soc Behav. 1978;19(1):2-21.

24 Lazarus RS. Stress, appraisal, and coping. New York: Springer Publishing Company; 1984.

25 Benassi VA, Sweeney PD, Dufour CL, Fowles DC. Is there a relation between locus of control orientation and depression? J Abnorm Psychol. 1988;97(3):357-67.

26 Eccles FJ, Simpson J. A review of the demographic, clinical and psychosocial correlates of perceived control in three chronic motor illnesses. Disabil Rehabil. 2011;33(13-14): 1065-88.

27 Bjørkløf GH, Engedal K, Selbæk G, Kouwenhoven SE, Helvik AS. Coping and depression in old age: a literature review. Dement Geriatr Cogn Disord. 2013;35(3/4):121-54. 
28 Bjørkløf GH, Engedal K, Selbaek G, Maia DB, Borza T, Benth JS, et al. Can depression in psychogeriatric inpatients at one year followup be explained by locus of control and coping strategies? Aging Ment Health. 2017 Jan 04:1-10.

29 Halse I, Bjørkløf GH, Engedal K, Selbæk G, Barca ML. Control Beliefs among People with Dementia: A Systematic Review. Dement Geriatr Cogn Disord. 2021. http://dx.doi. org/10.1159/000516789.

30 Fankhauser S, Drobetz R, Mortby M, Maercker A, Forstmeier S. Depressive symptoms in later life: differential impact of social support and motivational processes on depression in individuals with and without cognitive impairment. Eur J Ageing. 2014 Dec;11(4):321- 32.

31 Halse I, Bjørkløf GH, Engedal K, Rokstad AMM, Persson K, Eldholm RS, et al. Applicability of the locus of control of behaviour scale for people with dementia. Aging Ment Health. 2019 Aug 12;24:1-6.

32 Quinn C, Toms G, Jones C, Brand A, Edwards RT, Sanders F, et al. A pilot randomized controlled trial of a self-management group intervention for people with early-stage dementia (the SMART study). Int Psychogeriatr. 2016 May;28(5):787-800.

33 Rokstad AM, Halse I, Tretteteig S, Barca ML, Kirkevold $\varnothing$, McCabe L, et al. Effects and costs of a day care centre program designed for people with dementia-A 24 month controlled stydy. J Clin Trials. 2014;4(4).

34 WHO. The ICD-10 classification of mental and behavioural disorders: diagnostic criteria for research. Geneva, Switzerland: World Health Organization; 1993.

35 Craig A, Andrews G. The prediction and prevention of relapse in stuttering: the value of self-control techniques and locus of control measures. Behav Modif. 1985;9(4):427-42.

36 Nordtug B, Krokstad S, Holen A. Personality features, caring burden and mental health of cohabitants of partners with chronic obstructive pulmonary disease or dementia. Aging Ment Health. 2011 Apr;15(3):318-26.

37 Bruvik FK, Ulstein ID, Ranhoff AH, Engedal $\mathrm{K}$. The effect of coping on the burden in family carers of persons with dementia. Aging Mental Health. 2013;17(8):973-8.

38 Bjørkløf GH, Engedal K, Selbæk G, Maia DB, Coutinho ESF, Helvik AS. Locus of control and coping strategies in older persons with and without depression. Aging Ment Health. 2016;20:831-9.
39 Helvik AS, Bjørkløf GH, Corazzini K, Selbæk G, Laks J, Østbye T, et al. Are coping strategies and locus of control orientation associated with health-related quality of life in older adults with and without depression? Arch Gerontol Geriatr. 2016 May-Jun;64:130-7.

40 Montgomery SA, Asberg M. A new depression scale designed to be sensitive to change. Br J Psychiatry. 1979;134(4):382-9.

41 Knapskog AB, Barca ML, Engedal K. A comparison of the validity of the Cornell Scale and the MADRS in detecting depression among memory clinic patients. Dement Geriatr Cogn Disord. 2011;32(4):287-94.

42 Folstein MF, Folstein SE, McHugh PR. Minimental state. A practical method for grading the cognitive state of patients for the clinician. J Psychiatr Res. 1975;12(3):189-98.

43 Strobel C, Engedal K. MMSE-NR. Norsk revidert mini mental status evaluering. Revidert og utvidet manual. (Norwegian revised version of the MMSE) Nasjonal Kompetansetjeneste for Aldring og Helse. 2008.

44 Hughes CP, Berg L, Danziger WL, Coben LA, Martin RL. A new clinical scale for the staging of dementia. Br J Psychiatry. 1982;140(6): $566-72$.

45 O’Bryant SE, Waring SC, Cullum CM, Hall J, Lacritz L, Massman PJ, et al. Staging dementia using clinical dementia rating scale sum of boxes scores: a Texas Alzheimer's research consortium study. Arch Neurol. 2008;65(8):1091-5.

46 Lawton MP, Brody EM. Assessment of older people: self-maintaining and instrumental activities of daily living. Gerontologist. 1969; 9(3):179-86.

47 Lyketsos CG, Galik E, Steele C, Steinberg M, Rosenblatt A, Warren A, et al. The general medical health rating: a bedside global rating of medical comorbidity in patients with dementia. J Am Geriatr Soc. 1999;47(4):487-91.

48 Reed BR, Jagust WJ, Coulter L. Anosognosia in Alzheimer's disease: relationships to depression, cognitive function, and cerebral perfusion. J Clin Exp Neuropsychol. 1993; 15(2):231-44.

49 Bjørkløf GH, Helvik AS, Ibsen TL, Telenius EW, Grov EK, Eriksen S. Balancing the struggle to live with dementia: a systematic metasynthesis of coping. BMC Geriatr. 2019;19(1): 295.
50 Tonga JB, Šaltytė Benth J, Arnevik EA, Werheid K, Korsnes MS, Ulstein ID. Managing depressive symptoms in people with mild cognitive impairment and mild dementia with a multicomponent psychotherapy intervention: a randomized controlled trial. Int Psychogeriatr. 2020;33:217-31.

51 Testad I, Clare L, Anstey K, Selbæk G, Bjørkløf GH, Henderson C, et al. Self-management and HeAlth promotion in early-stage dementia with e-learning for carers (SHAPE): study protocol for a multi-centre randomised controlled trial. BMC Public Health. 2020;20(1): 1508.

52 McDermott O, Charlesworth G, Hogervorst E, Stoner C, Moniz-Cook E, Spector A, et al. Psychosocial interventions for people with dementia: a synthesis of systematic reviews. Aging Ment Health. 2019;23(4):393-403.

53 Schmitter-Edgecombe M, Howard JT, Pavawalla SP, Howell L, Rueda A. Multidyad memory notebook intervention for very mild dementia: a pilot study. Am J Alzheimers Dis Other Demen. 2008 Oct-Nov; 23(5):477-87.

54 Stockwell-Smith G, Moyle W, Kellett U. The impact of early psychosocial intervention on self-efficacy of care recipient/carer dyads living with early-stage dementia-A mixedmethods study. J Adv Nurs. 2018;74(9):216780.

55 Clare L, Kudlicka A, Oyebode JR, Jones RW, Bayer A, Leroi I, et al. Individual goal-oriented cognitive rehabilitation to improve everyday functioning for people with early-stage dementia: a multicentre randomised controlled trial (the GREAT trial). Int J Geriatr Psychiatry. 2019;34(5):709-21.

56 Langer EJ, Rodin J. The effects of choice and enhanced personal responsibility for the aged: a field experiment in an institutional setting. J Pers Soc Psychol. 1976;34(2):191-8.

57 Lachman ME, Weaver SL, Bandura M, Elliott E, Lewkowicz CJ. Improving memory and control beliefs through cognitive restructuring and self-generated strategies. J Gerontol. 1992;47(5):P293-9.

58 Jang Y, Haley WE, Small BJ, Mortimer JA. The role of mastery and social resources in the associations between disability and depression in later life. Gerontologist. 2002 Dec; 42(6):807-13. 